\title{
HUBUNGAN POLA ASUH IBU DENGAN KEBERHASILAN TOILET TRAINING PADA ANAK USIA PRASEKOLAH DI POSYANDU BALITA BANJAR INTARAN WILAYAH KERJA UPT KESMAS TAMPAKSIRING II
}

\author{
RELATIONSHIP OF MATERNAL PARENTING TOWARD THE \\ TOILET TRAINING SUCCESS IN PRESCHOOL CHILDREN \\ AGE AT POSYANDU BALITA BANJAR INTARAN REGION OF \\ UPT KESMAS TAMPAKSIRING II
}

\author{
Kadek Sopa Yuliana1, Ni Wayan Suniyadewi2, I Made Udayana3. \\ Sekolah Tinggi Ilmu Kesehatan Wira Medika PPNI Bali12, \\ Rumah Sakit Umum Pusat Sanglahi3
}

\begin{abstract}
ABSTRAK
Toilet Training secara dini merupakan salah satu tugas perkembangan untuk membentuk kemandirian, kedisiplinan dan kepekaan emosi pada anak untuk mencapai tugas perkembangan pada anak usia prasekolah. Hasil studi pendahuluan di Posyandu Balita Banjar Intaran, dari hasil wawancara dengan $10 \mathrm{ibu}$, didapatkan $40 \%$ anak sudah mandiri dalam melakukan toilet training dan $60 \%$ anak lainnya masih sering mengompol, memerlukan bantuan ibu pada saat BAK dan BAB. Tujuan penelitian ini adalah mengetahui hubungan pola asuh ibu dengan keberhasilan toilet training pada anak usia prasekolah. Jenis penelitian deskriptif analitik, dengan rancangan cross-sectional. Jumlah sampel sebanyak 57 orang dengan metode Purposive sampling. Pengumpulan data menggunakan kuesioner. Pola asuh ibu sebagian besar adalah demokratis sebanyak 36 orang $(62,3 \%)$. Keberhasilan toilet training sebagian besar dalam kategori berhasil sebanyak 38 orang (66,7\%). Hasil uji Rank Spearman didapatkan P value $0,000<$ dari tingkat signifikansi ditentukan yaitu 0,05 , hasil ini menunjukkan ada hubungan pola asuh ibu dengan keberhasilan toilet training pada anak usia prasekolah. Pola asuh ibu berhubungan signifikan dengan keberhasilan toilet training pada anak usia prasekolah. Disarankan agar orang tua menstimulasi atau melatih anak agar bisa memenuhi kebutuhan mereka sendiri yaitu dimulai dari kebutuhan paling dasar misalnya melatih toilet training, makan/minum sendiri dan merapikan mainan sendiri.
\end{abstract}

Kata Kunci : Pola Asuh Ibu, Toilet Training, Anak Usia Prasekolah

\section{ABSTRACT}

Toilet Training in early age is one of the developmental tasks to form selfsupporting, discipline and emotional sensitivity in children to achieve the developmental task, one of which can be done through the toilet training early on. The results of the preliminary study at Maternal and Child Health Centre Banjar Intaran, with interviewed 10 mothers, found that 40\% children have been selfsupporting in toilet training and $60 \%$ of another children still wet the pants, need 
mother's assistance at the time of defecation and urination. The aim of this research was to know the relationship of maternal parenting toward the toilet training success in preschool age children. The type of research was analytical descriptive with cross-sectional design. The number of sample were 57 people with Purposive sampling method. The data collection used questionnaires. The maternal parenting was mosthy democratic, as many as 36 people (\%). The success of toilet training mostly in success category as many as in 38 people $(66,7 \%)$. The result of Rank Spearman test with $p$ value $0.000<$ from the significance level determined that is 0,05 , it is showed there is a relationship of maternal parenting toward the toilet training success at preschool age children. Maternal parenting is significantly associated with the success of toilet training in preschool age children. It is recommended that parents stimulate or train the children to meet their own needs starting from the most basic needs such as train the toilet toilets, eat/drink themselves and clear up the toys themselves.

Keywords: Maternal Parenting, Toilet Training, Preschool Children Age

\begin{tabular}{ll}
\hline Alamat korespondensi & $\begin{array}{l}\text { : Stikes Wira Medika PPNI Bali } \\
\text { Email sopayuliana6@gmail.com }\end{array}$ \\
\hline
\end{tabular}

\section{LATAR BELAKANG}

Toilet training pada anak merupakan suatu usaha untuk melatih anak agar mampu mengontrol dalam melakukan buang air kecil dan buang air besar. Dalam melakukan latihan buang air besar dan buang air kecil pada anak membutuhkan persiapan baik secara fisik, psikologis, maupun secara intelektual, melalui persiapan tersebut diharapkan anak mampu mengontrol buang air besar dan buang kecil secara mandiri (Hidayat, 2014). Usia yang tepat untuk melakukan toilet training adalah usia balita karena kontrol volunter dari spingterani dan uretra dicapai pada waktu anak dapat berjalan dan biasanya terjadi antara usia 18-24 bulan. Namun faktor kesiapan psikologis sangat berpengaruh pada kesiapan toilet training (Nursalam, 2013).

Penyebab anak-anak memiliki kebiasaan mengompol adalah toilet training yang terlalu dini, mengabaikan toilet training, gangguan emosional dan faktor organik dalam tubuh (Yusuf \& Asih, 2006). Menurut Hidayat (2014) penyebab yang paling umum dalam kegagalan toilet training seperti adanya perlakuan atau aturan yang ketat oleh orang tua terhadap anaknya yang dapat menganggu kepribadian atau cenderung bersikap keras kepala dan sulit diatur. Hal ini dilakukan oleh orang tua apabila sering memarahi anak pada saat buang air besar dan buang air kecil, atau melarang untuk buang air besar (BAB) dan buang air kecil (BAK) anak saat berpergian. Menurut Ariyanti (2014) menyatakan sangat penting untuk menunggu kesiapan anak agar ia terhindar dari rasa frustasi atau putus asa. Memaksa anak menjalani toilet training sebelum anak menunjukan kesiapan, hanya akan membuat anak menolak toilet training. Pada saat anak menolak untuk dilatih, orang tua tidak perlu memaksa. Proses toilet training tidak perlu menjadi pertengkaran antara orang tua dan anak.

Salah satu bentuk pertumbuhan dan perkembangan anak di usia prasekolah yang perlu diperhatikan oleh orang tua adalah masalah toilet training. Toilet 
training merupakan salah satu tahapan perkembangan anak dalam usia 1-3 tahun atau usia toddler. Menyatakan bahwa anak menunjukkan sinyal kuat dalam menjalani toilet training secara fisik, mental, emosional sebelum 3 tahun. Walaupun begitu, setidaknya $15 \%$ anak dalam usia tersebut belum dapat menguasainya. Namun, sampai umur 4 tahun anak dapat menjalani toilet training $96 \%$.

Menurut American Academik Of Pediatries (AAP, 2004 dalam Febriyanti, 2015) sikap atau pola asuh ibu yang memberikan hukuman atau memarahi anak akan sering menimbulkan perasaan yang tidak nyaman pada anak dan bisa menyebabkan kegagalan toilet training dan menjadi lebih lama. Menurut data American Academy of child and Adolescent psychiatry, di Amerika Serikat 15 dari 25 anak berusia diatas 4-6 tahun masih sering mengompol saat tidur. Di Indonesia diperkirakan jumlah anak mencapai 30\% dari 250 juta jiwa, dan menurut Survei Kesehatan Rumah Tangga (SKRT) tahun 2013 diperkirakan jumlah anak yang masih susah mengontrol buang air besar (BAB) dan buang air kecil (BAK) di usia prasekolah mencapai 75 juta anak. Namun demikian masih ada sekitar $30 \%$ anak umur 3 tahun dan 10\% anak umur 6 tahun yang masih takut ke kamar mandi apabila pada malam hari. Persentase kejadian anak mengompol lebih besar pada anak lakilaki yaitu $60 \%$ dibandingkan pada anak perempuan yaitu sebesar $40 \%$. Statistik menunjukkan $25 \%$ anak mengompol pada usia 5 tahun akan menurun $5 \%$ pada usia 10 tahun (Lestari, 2013). Di Indonesia sendiri anak usia 6 tahun masih mengompol sekitar 12\% (Asti dalam Sumawati, 2012). Penelitian yang dilakukan oleh Kuruniawati (2007) menyatakan bahwa pada anak usia prasekolah di TK sekar Ratih Krembangan Jaya Selatan, Surabaya terdapat 52\% anak dengan frekuensi sering sekali, $4 \%$ sering, 36\% jarang, dan $8 \%$ sangat jarang, kebiasaan mengompol ini apabila berlangsung lama akan mengganggu pencapaian tugas perkembangan anak.

Hasil studi pendahuluan yang dilakukan di tiga Posyandu Balita di UPT Kesmas Tampaksiring II yang berbeda yaitu di Posyandu Balita Banjar Intaran, Posyandu Balita Banjar Pangelan dan Posyandu Balita Banjar Cemadi diperoleh data bahwa di Posyandu Balita Banjar Intaran terdapat sebanyak 70 orang anak usia prasekolah, dari hasil wawancara dengan 10 ibu yang memiliki anak usia prasekolah didapatkan $4(40 \%)$ anak sudah mandiri dalam melakukan toilet training dan $6(60 \%)$

anak lainnya masih sering ngompol, memerlukan bantuan orang tua pada saat BAB dan BAK. Studi pendahuluan yang kedua dilakukan di Posyandu Balita Banjar Pangelan, terdapat sebanyak 40 orang anak usia prasekolah dari hasil wawancara dengan $10 \mathrm{ibu}$ diperoleh data yaitu sebanyak 7 orang $(70 \%)$ siswa usia prasekolah sudah mandiri dalam melakukan toilet training, $2(20 \%)$ anak masih sering mengompol, memerlukan bantuan pada saat BAB dan BAK dan 1 (10\%) anak masih mengompol. Studi pendahuluan yang ketiga dilakukan di Posyandu Balita Banjar Cemadik, terdapat sebanyak 53 orang anak usia prasekolah dari hasil wawancara dengan $10 \mathrm{ibu}$ diperoleh data sebanyak 7 orang anak $(70 \%)$ sudah tidak mengalami masalah pada kemandirian (toilet training) dan 3 anak (30\%) dibantu pada saat membersihkan diri setelah buang air besar dan buang air kecil masih mengompol dan membutuhkan bantuan orang tua ketika ingin melakukan buang air besar dan buang air kecil.

Hasil studi pendahuluan tentang pola asuh ibu di Posyandu Balita Banjar 
Intaran dari $10 \mathrm{ibu}$ yang memiliki anak usia prasekolah didapatkan $5(50 \%)$ orang tua menerapkan pola asuh demokratis, 2 orang (20\%) menerapkan pola asuh otoriter dan 3 orang (30\%) menerapkan pola asuh permisif. Studi pendahuluan yang kedua dilakukan di Posyandu Banjar Pangelan didapatkan $4(40 \%)$ orang tua menerapkan pola asuh demokratis, 3 orang (30\%) menerapkan pola asuh otoriter dan 3 orang (30\%) menerapkan pola asuh permisif. Studi pendahuluan yang ketiga dilakukan di Posyandu Banjar Cemadik, didapatkan 5 (50\%) orang tua menerapkan pola asuh demokratis, 1 orang $(10 \%)$ menerapkan pola asuh otoriter dan 4 orang $(40 \%)$ menerapkan pola asuh permisif.

Berdasarkan latar belakang diatas, maka peneliti tertarik untuk melakukan penelitian dengan judul "hubungan pola asuh ibu dengan keberhasilan toilet training pada anak usia prasekolah di Posyandu Balita Banjar Intaran Wilayah Kerja UPT Kesmas Tampaksiring II.',

\section{METODE}

Jenis penelitian ini adalah deskriptif analitik. Rancangan yang digunakan dalam penelitian ini adalah rancangan cross-sectional yang menekankan waktu pengukuran atau observasi data variabel independen dan dependen hanya satu kali tidak ada follow up (Nursalam, 2013).

Pengambilan data dilakukan di di Posyandu Balita Banjar Intaran Wilayah Kerja UPT Kesmas Tampaksiring II, Penelitian ini dilaksanakan pada tanggal 3 Mei 2017 sampai dengan tanggal 3 Juni 2017. Sampel dalam penelitian ini ditentukan berdasarkan kriteria inklusi. Jumlah sampel sebanyak 57 orang, cara probability sampling yaitu dengan purposive sampling. Variabel independen dalam penelitian ini adalah pola asuh ibu. Variabel dependen dalam penelitian ini adalah keberhasilan toilet training pada anak usia prasekolah

Prosedur analisis dalam penelitian ini proses pengolahan data mengikuti langkah - langkah sebagai berikut editing, coding, entri data dan cleaning atau tabulasi. Analisa data pada penelitian ini mengunakan uji "Rank Spearman,". Penentuan hipotesis diterima atau ditolak apabila nilai probability lebih kecil dari nilai signifikansi $(\mathrm{p}<0,05)$ maka ada hubungan pola asuh ibu dengan keberhasilan toilet training pada anak usia prasekolah di Posyandu Balita Banjar Intaran Wilayah Kerja UPT Kesmas Tampaksiring II.

\section{HASIL PENELITIAN}

1 Usia anak

\begin{tabular}{clcc}
\hline No & Usia anak & $\mathrm{f}$ & $\%$ \\
\hline 1 & 4 tahun & 14 & 24.6 \\
\hline 2 & 5 tahun & 37 & 64.9 \\
\hline 3 & 6 tahun & 6 & 10.5 \\
\hline & Total & 57 & 100,0 \\
\hline
\end{tabular}

Berdasarkan tabel 4.1 dapat diketahui karakteristik anak berdasarkan usia menunjukkan sebagian besar anak berusia 5 tahun sebanyak 37 orang $(64,9 \%)$. 
2 Jenis kelamin anak

\begin{tabular}{llcc}
\hline $\begin{array}{l}\text { No } \\
\text { anak }\end{array}$ & $\begin{array}{l}\text { Jenis kelamin } \\
\text { anak }\end{array}$ & f \\
\hline 1 & Laki-laki & 32 & 56.1 \\
\hline 2 & Perempuan & 25 & 43.9 \\
\hline & Total & 57 & 100,0 \\
\hline
\end{tabular}

Berdasarkan tabel 4.2 dapat diketahui karakteristik anak berdasarkan jenis kelamin menunjukkan sebagian besar berjenis kelamin laki-laki sebanyak 32 orang $(56,1 \%)$.

3 Usia Ibu

\begin{tabular}{clcc}
\hline No & $\begin{array}{l}\text { Umur } \\
\text { Ibu }\end{array}$ & $\mathrm{f}$ & $\%$ \\
\hline 1 & $20-30$ th & 30 & 52.6 \\
\hline 2 & $31-40$ th & 27 & 47.4 \\
\hline & Total & 57 & 100,0 \\
\hline
\end{tabular}

Berdasarkan tabel 4.3 dapat diketahui karakteristik ibu berdasarkan usia menunjukkan sebagian besar berusia 20-30 tahun yaitu 30 orang (52,6\%).

4 Pendidikan ibu

\begin{tabular}{clcc}
\hline No & Pendidikan Ibu & $\mathrm{f}$ & $\%$ \\
\hline 1 & SMP & 9 & 15.8 \\
\hline 2 & SMA & 27 & 47.4 \\
\hline 3 & Sarjana & 21 & 36.8 \\
\hline & Total & 57 & 100,0 \\
\hline
\end{tabular}

Berdasarkan tabel 4.4 dapat diketahui karakteristik ibu berdasarkan pendidikan menunjukkan sebagian besar SMA yaitu 27 orang $(47,4 \%)$.

$5 \quad$ Pekerjaan ibu

\begin{tabular}{clcc}
\hline No & Pekerjaan Ibu & $\mathrm{f}$ & $\%$ \\
\hline 1 & Tidak bekerja & 17 & 29.8 \\
\hline 2 & Bekerja & 40 & 70.2 \\
\hline & Total & 57 & 100,0 \\
\hline
\end{tabular}

Berdasarkan tabel 4.5 dapat diketahui karakteristik ibu berdasarkan pekerjaan menunjukkan sebagian besar bekerja yaitu 40 orang $(70,2 \%)$. 
Hasil pengamatan terhadap obyek penelitian berdasarkan variabel penelitian 1. Pola asuh ibu

\begin{tabular}{clcc}
\hline No & Pola Asuh Ibu & $\mathrm{f}$ & $\%$ \\
\hline 1 & Demokratis & 36 & 63.2 \\
\hline 2 & Otoriter & 14 & 24.6 \\
\hline 3 & Permisif & 3 & 5.3 \\
\hline 4 & Penelantar & 4 & 7.0 \\
\hline & Total & 57 & 100,0 \\
\hline
\end{tabular}

Berdasarkan tabel 4.6 dapat diketahui bahwa sebagian besar pola asuh ibu adalah demokratis yaitu 36 orang $(62,3 \%)$ dan sebangian kecil Pola asuh ibu adalah permisif 3 orang $(5,3 \%)$.

2. Keberhasilan toilet training pada anak usia prasekolah

\begin{tabular}{clcc}
\hline No & $\begin{array}{l}\text { Keberhasilan } \\
\text { Toilet Training }\end{array}$ & $\mathrm{f}$ & $\%$ \\
\hline 1 & Mandiri & 38 & 66.7 \\
\hline 2 & Tidak mandiri & 19 & 33.3 \\
\hline & Total & 57 & 100,0 \\
\hline
\end{tabular}

Berdasarkan tabel 4.7 dapat diketahui bahwa sebagian besar toilet training pada anak usia prasekolah dalam kategori mandiri yaitu 38 orang $(66,7 \%)$.

\section{HASIL ANALISIS DATA}

Berdasarkan hasil penelitian menunjukkan dari 57 responden yang diteliti, memberikan gambaran bahwa ibu yang memiliki pola asuh demokratis anak melakukan toilet training dalam kategori mandiri sebanyak 35 orang $(61,4 \%)$. Ibu yang memiliki pola asuh otoriter anak melakukan toilet training dalam kategori tidak mandiri sebanyak 11 orang $(19,3 \%)$. Ibu yang memiliki pola asuh penelantar anak melakukan toilet training dalam kategori tidak mandiri sebanyak 4 orang (7\%). Sebagian kecil ibu memiliki pola asuh permisif anak melakukan toilet training dalam kategori tidak mandiri sebanyak 3 orang $(5,3 \%)$.

Hasil uji Rank Spearman juga didapat P value sebesar $0,000<$ dari tingkat signifikan ditentukan yaitu 0,05 nilai coefisien correlation sebesar 0,856 dapat diartikan terdapat hubungan yang kuat antara variabel pola asuh ibu dengan keberhasilan toilet training. Terhadap hubungan yang positif antara variabel terdapat hubungan artinya jika pola asuh ibu menerapkan pola asuh ibu menerapkan pola asuh demokratis maka anak melakukan toilet training akan semakin mandiri.

\section{Pola asuh ibu}

\section{PEMBAHASAN}

Berdasarkan hasil penelitian dapat diketahui sebagian besar pola asuh ibu adalah demokratis yaitu 36 orang $(62,3 \%)$. 
Hasil penelitian yang menunjukkan sebagian besar pola asuh ibu adalah demokratis, hal ini didukung oleh karakteristik responden berdasarkan pendidikan menunjukkan sebagian besar yaitu 27 orang $(47,4 \%)$ SMA. Menurut Hurlock dalam Nuraeni (2015) Ibu yang berpendidikan tinggi memiliki kesempatan dan kemampuan untuk memperoleh materi yang lebih besar yang diperlukan untuk menyediakan fasilitas dan sarana belajar anak. Selain itu dengan pengetahuan yang dimiliki, ibu yang berpendidikan tinggi pada umumnya bersikap terbuka dan mampu memperlakukan anak secara positif. Mereka memberikan perhatian yang besar terhadap perkembangan dan pendidikan anak, serta memahami tentang kebutuhan anak.

Peneliti berpendapat, ibu yang memiliki latar pendidikan SMA dapat dikatakan memiliki pengetahuan yang baik tentang pengasuhan anak. Faktor yang mempengaruhi pengetahuan adalah pendidikan ibu, semakin tinggi tingkat pendidikan seseorang maka pemahaman dan kepedulian terhadap sesuatu hal akan semakin tinggi. Ibu dengan latar belakang pendidikan yang tinggi dalam praktek pola asuhnya tampak sering membaca artikel ataupun mengikuti kemajuan pengetahuan mengenai perkembangan anaknya, sehingga dalam mengasuh anak mereka menjadi siap.

Faktor usia juga dapat mempengaruhi ibu menerapkan pola asuh yang demokratis saat mengasuh anaknya. Hasil penelitian menunjukkan karakteristik ibu berdasarkan usia sebagian besar yaitu 30 orang $(52,6 \%)$ berusia 20-30 tahun. Usia 20-30 tahun termasuk kategori usia dewasa, menurut pendapat peneliti ibu yang berusia dewasa madya merupakan usia dimana kepribadian dan kemampuan mental mencapai puncaknya, ibu pada usia ini lebih siap menjalankan peran asuhan, selain itu ibu pada usia dewasa sudah mempunyai pengalaman sebelumnya dalam mengasuh anak dan lebih mampu mengamati tanda-tanda pertumbuhan dan perkembangan yang normal. Ibu dengan usia dewasa akan mengasuh anaknya lebih luwes, sabar, penuh kasih sayang, tidak melindungi anak secara berlebihan, tidak permisivitas (tidak membiasakan anak untuk berbuat sesuka hati), tidak memanjakan, dapat menerima keadaan anak secara keseluruhan, dan dapat berbuat sadar. Hal ini menunjukkan bahwa semakin dewasa usia ibu, maka akan mampu mendidik anaknya sesuai dengan usia dari tugas perkembangan anak.

\section{Keberhasilan toilet training pada anak usia prasekolah}

Hasil penelitian yang didapatkan menunjukkan sebagian besar toilet training pada anak usia prasekolah dalam kategori berhasil yaitu 38 orang $(66,7 \%)$.

Hasil penelitian ini menunjukkan anak lebih banyak yang sudah berhasil dalam toilet training selain karena pembiasaan ibu yang mengajarinya juga dipengaruhi oleh usia anak dimana anak yang menjadi responden pada penelitian ini sebagian besaryaitu 37 orang (64,9\%) berumur 5 tahun. Menurut Effendi (2012) menyatakan anak melewati tahap perkembangan dapat berjalan seiring dengan tingkat usianya. Semakin betambah usia anak, makin tinggi tingkatan keberhasilan anak tesebut karena anak sudah semakin siap secara emosi dan perkembangan ketika diajarkan untuk melakukan toilet training.

Faktor lain yang mempengaruhi keberhasilan anak yaitu jenis kelamin, anak yang menjadi responden pada penelitian ini sebagian besar yaitu 32 orang $(56,1 \%)$ laki-laki, menurut Ramawati (2011) menyimpulkan bahwa anak laki-laki dituntut lebih mandiri, bertanggung jawab terhadap aktivitas mereka sendiri. Jenis kelamin 
dapat mempengaruhi ibu dalam memandirikan anak karena anak perempuan cenderung lebih dilindungi dari pada anak laki-laki. Faktor usia anak juga dapat mempengaruhi keberhasilan.

Faktor karakteristik ibu, juga dapat mempengaruhi keberhasilan anak melakukan toilet training, salah satunya pendidikan ibu, dalam penelitian ini berdasarkan pendidikan menunjukkan sebagian besar yaitu 27 orang $(47,4 \%)$. Menurut Sumawati, (2012) tingkat pendidikan turut menentukan mudah tidaknya seseorang menyerap dan memahami pegetahuan yang mereka peroleh. Dari kepentingan keluarga, pendidikan itu sendiri amat diperlukan agar seseorang lebih tanggap terhadap masalah perkembangan anak salah satunya penerapan toilet training di dalam keluarganya. Tingkat pendidikan berpengaruh pada pengetahuan ibu tentang penerapan toilet training. Pengetahuan yang dimiliki ibu pada dasarnya dapat berpengaruh pada cepat atau lambatnya ibu melakukan penerapan toilet training, dimana ibu yang memiliki pengetahuan baik tentang toilet training pada anak, hal tersebut berdampak positif bagi ibu maupun anak yaitu anak dapat mandiri melakukan toilet training.

Menurut pendapat peneliti, keberhasilan anak dapat dikembangkan dengan membiarkan anak untuk mengeksplorasi lingkungan dalam kehidupan sehariharinya. Untuk berani mengeksplorasi lingkungan maka anak butuh pemenuhan rasa aman, kasih sayang dan perhatian. Rasa aman dapat dibangun dengan cara memberikan respon yang positif setiap kali anak mengisyaratkan sesuatu. Disamping rasa aman, kemampuan bersikap mandiri juga dipengaruhi oleh kepercayaan diri anak. Untuk mengembangkan kepercayaan diri salah satu caranya yaitu dengan memberikan dukungan, pujian pada anak setiap kali berhasil melakukan sesuatu.

\section{Hubungan pola asuh ibu dengan keberhasilan toilet training pada anak usia prasekolah}

Berdasarkan hasil uji Rank Spearman didapatkan angka p value sebesar $0,000<$ dari tingkat signifikansi ditentukan yaitu 0,05 . Hasil ini menunjukkan ada hubungan pola asuh ibu dengan keberhasilan toilet training pada anak usia prasekolah di Posyandu Banjar Intaran Wilayah Kerja Puskesmas Tampaksiring II. Hasil uji Rank Spearman juga didapat nilai coefisien corelation sebesar 0,856 dapat diartikan terdapat hubungan yang kuat antara variabel pola asuh ibu dengan keberhasilan toilet training. Terdapat hubungan yang positif antar variabel terdapat hubungan artinya jika pola asuh ibu menerapkan pola asuh demokratis maka anak melakukan toilet training akan semakin berhasil juga.

Hasil dalam penelitian ini menunjukkan responden yang pola asuhnya demokratis sebagian besar anaknya mandiri dalam toilet training. Hal ini sesuai dengan teori Muschari (2014) bahwa pola asuh demokratis menunjukkan sikap ibu berinteraksi dengan anak dapat mempengaruhi perilaku anak yang nantinya akan berpengaruh terhadap kemandirian dan keberhasilan anak. Semakin baik pola asuh ibu terhadap anak, semakin tinggi keberhasilannya untuk anak melakukan toilet training.

Peneliti berpendapat, pola asuh ibu berhubungan dengan keberhasilan dalam melakukan toilet training hal ini disebabkan karena pola asuh yang baik yaitu pola asuh yang memberikan dorongan pada anak untuk mandiri namun tetap menerapkan berbagai batasan yang akan mengontrol perilaku mereka. Hubungan 
saling memberi dan menerima, mendengarkan dan didengarkan, akan keberhasilan anak, terutama karena interaksinya diwarnai kehangatan. Ibu yang penuh kehangatan, berespon, terpusat pada anak di dalam pendekatan pada anak-anak mereka. Kehangatan dan hasil asuhan ibu berhubungan dengan respon mereka terhadap anaknya sendiri dan dapat, membangun rasa aman serta harga diri mereka akan memberikan energi kepercayaan dalam diri anak untuk lebih berusaha mempelajari dan mencoba hal-hal yang baru yang terkait keberhasilan dalam melakukan toilet training.

\section{KESIMPULAN}

1. Pola asuh ibu pada anak usia prasekolah di Posyandu Balita Banjar Intaran Wilayah Kerja UPT Kesmas Tampaksiring II sebagian pola asuh ibu adalah demokratis besar yaitu 36 orang $(62,3 \%)$.

2. Keberhasilan toilet training pada anak usia prasekolah di Posyandu Balita Banjar Intaran Wilayah Kerja UPT Kesmas Tampaksiring II sebagian besar dalam katagori berhasil yaitu 38 orang (66,7\%).

3. Hasil uji Rank Spearman didapatkan angka sebesar $0,000<$ dari tingkat signifikansi ditentukan yaitu 0,05 , hasil ini menunjukkan ada hubungan pola asuh ibu dengan keberhasilan toilet training pada anak usia prasekolah di Posyandu Balita Banjar Intaran Wilayah Kerja UPT Kesmas Tampaksiring II.

1. Orang tua

\section{SARAN}

Diharapkan agar orang tua menstimulasi atau melatih anak agar anak bias memenuhi kebutuhan mereka sendiri yaitu dimulai dari kebutuhan paling dasar misalnya melatih toilet training, makan/minum sendiri, merapikan mainan sendiri juga harus sabar dan penuh perhatian terhadap apa yang dilakukan anak, berilah kesempatan pada anak untuk memecahkan masalahnya sendiri, dan berilah bantuan seperlunya bila anak meminta bantuan.

2. Profesi Keperawatan

Diharapkan dapat meningkatkan perannya dalam melakukan pengkajian dan merencanakan program-program pelatihan atau penyuluhan kesehatan terkait toilet training.

3. Penelitian Selanjutnya

1) Diharapkan melakukan penelitian tentang kemandirian anak yang lain seperti : Kemandirian dalam perawatan diri, makan minum dan berias.

2) Mengendalikan faktor-faktor yang dapat mempengaruhi keberhasilan toilet training dengan cara menghomogenkan karakteristik anak seperti: usia, jenis kelamin.

3) Melakukan observasi langsung tentang pola asuh yang diberikan kepada anak dan keberhasilan toilet training.

4) Penelitian selanjutnya diharapkan meneliti perilaku orang tua dengan menggunakan metode penelitian kuwalitatif.

\section{DAFTAR PUSTAKA}

Adriana, D. 2011. Tumbuh kembang dan Terapi Bermain pada Anak. Jakarta :Salemba Medika 
Ariyanti. 2014. Mengenalkan Toilet Training pada Anak. Jakarta: EGC

BKKBN. 2010 Kiat Praktis Keluarga dalam Pengasuhan dan Pengembangan Anak Usia Dini. Jakarta: Unicef Indonesiasa

Clark. 2016. 6 Tipe Pola Asuh Ibu Zaman Modern. (Online). http://www.pendidikankarakter.com/peran-pola-asuh-dalam-membentukkarakter-anak/ diakses : (12 Februari 2017)

Dewi, W. S. 2014 Hubungan Pola Asuh Orang Tua dengan Kemampuan Anak Membedakan Tanda-Tanda Toilet Training di TK Tunas Harapan Denpasar. Stikes Wira Medika PPNI Bali.

Effendi. 2012. Mengenali dan Memahami Tumbuh Kembang Anak. Yogjakarta: Katahati

Eveline \& Djamaludin. 2010. Mengenalkan Toilet Training Kepada Anak. Jakarta: EGC

Hidayat, A.A. 2014. Pengantar Ilmu Keperawatan Anak. Jakarta: Salemba Medika. Iswidarmanjaya. 2004. Satu Hari Menjadi Lebih Percaya Diri. Jakarta: PT Elex Media komputindo

Jannah. 2012. Mengajari Anak Pergi Ketoilet. Jakarta: Arcan.

Kartono. 2012. Psikologi Anak. Bandung. Mandar Maju

Kuruniawati. 2007. Hubungan Antara Pengetahuan Dan Sikap Ibu Dalam Toilet Training Pada Toddler (18 - 36 Bulan) Di Desa Geger Kecamatan Geger Kabupaten Madiun. (online) http:// www.e-jurnal.com/2014/. diakses : (17 Februari 2017)

Lestari. 2013. Hubungan Pola Asuh Orang Tua Dengan Tingkat Keberhasilan Toilet Training Pada Anak Balita (4-5 Tahun) di Dusun Kernekan Desa Tunggak Kecamatan Toroh Kabupaten Grobogan. (online) http:// www.ejurnal.com/2014/. diakses : (17 Februari 2017)

Mooduta. 2014. Hubungan Antara Pola Asuh Orang Tua Dengan Kemandirian Anak Di Kelompok A TK Beringin II Kecamatan Tilamuta Kabupaten Boalemo, Goorntalo. (online) http://www.jurnal.lipi.go.id/ diakses : (14 Februari 2017)

Munafiah. 2013. Hubungan Tingkat Pengetahuan Ibu Dengan Kemandirian Toilet Training Pada Anak Retardasi Mental di SLB Negeri Surakarta. online) http:// www.e-jurnal.com/2014/. diakses : (17 Februari 2017)

Muscari, H. 2014. Perkembangan Anak Prasekolah. Jakarta: Salemba Medika Mutiah. 2010. Bina Karakter Anak Usia Dini. Jogjakarta: PT Ar-ruzz Media

Novinda. 2014. SPSS 13.0 Terapan: Tiset Statistik Parametrik. Jakarta :Rineka Cipta

Nurdiyah. 2011. Toilet Training Untuk Anak. Jakarta: EGC

Nuraeni. 2015. Pengaruh Pola Asuh Orang Tua Terhadap Pembentukan Kepribadian Anak Taman Kanak- Kanak. Jakarta: Salemba Medika

Nursalam. 2013. Metodelog illmu Keperawatan Edisi 2. Jakarta: Salemba Medika

Notoadmojo. 2012. Metodelogi Penelitian Kesehatan. Jakarta :Rineka Cipta

Padmonodewo. 2012. Tumbang Anak dan Remaja. Jakarta: CV Sagung Seto

Prayitno. 2009. SPSS Untuk Analisis Bivariat dan Multivariat. Jakarta : Salemba Medika

Rahayu. 2013. Hubungan Pengetahuan Ibu Tentang Toilet Training Dengan Perilaku Ibu Dalam Melatih Toilet Training pada Anak Usia Toodler di Desa Kadokan Sukoharjo. Diakses Pada Tanggal 18 Pebruari 2017 dari 
$\mathrm{http} / / \mathrm{www} \cdot$ researchgate.net/publication.

Ramawati. 2011. Karakter Anak Usia Dini. Yogjakarta: PT Ar-ruzz Media

Rusita. 2014. Hubungan Pengetahuan Dan Peran Orang Tua Dengan Keberhasilan Toilet Training Pada Anak Usia 5 Tahun di TK Desa Suwaloh Kecamatan Balen Kabupaten Bojonegoro. (online) http:// www.ejurnal.com/2014/. diakses : (17 Februari 2017)

Saputri. 2015. Hubungan Pola Asuh Orangtua dengan perkembangan bahasa anak Attention Deficit Hiperactivity Disorder usia prasekolah di Pradnyagama. Skripsi StiKes Wira Medika PPNI Bali

Sugiyono. 2013. Statistika untuk Penelitian. Bandung: Alfabeta.

Shanti. 2011. Pola Asuh Penuh Cinta.(online) https://keluargasehat.wordpress.com Diakses : (19 Februari 2017)

Sulistyanigsih, W. 2014. Kesiapan Bersekolah Ditinjau Dari Jenis Pendidikan Pra Sekolah Anak Dan Tingkat Pendidikan Orang Tua. Psikologi Fakultas Kedokteran Universitas Sumatera Utara.

Supartini , Y. 2013. Buku Ajar Konsep Keperawatan Anak. Jakarta: EGC.

Sumawati. 2012. Anak Mandiri dan Tahapan Perkembangan Kemandirian. (online) http://www.al-maghribicendekia.com/2013/09/ciri-anak-mandiridan-tahapan.html. diakses : (17 Februari 2017)

Suseno. 2011. Hubungan Pola Asuh Orang Tua Dengan Kemandirian Anak Usia Prasekolah di TK Aisyiyah Mendungan Sukoharjo. (online) http://www.jurnal.lipi.go.id/ diakses : (14 Februari 2017)

Soetjiningsih, C.H. 2012. Perkembangan Anak Sejak Pembuahan Sampai Dengan Kanak-Kanak Akhir. Jakarta: Prenada Media Group.

Widyarini,N. 2009. Relasi Orang Tua dan Anak. Jakarta: PT Elex Media Komputindo.

Wong, L. D. 2009. Buku Ajar Keperawatan Pediatrik Volume1. Jakarta: EGC . 2009. Buku Ajar Keperawatan Pediatrik Volume2.Jakarta: EGC

Zaivera. 2013. Mengenali dan Memahami Tumbuh Kembang Anak. Yogyakarta: Kata Hati.

Yusuf \& Asih. 2006. Psikologi Perkembangan Anak dan Remaja. Bandung: PT. Remaja Rosdakarya. 